\title{
ESPÉCIE DE VEREDA NA FITORREMEDIAÇÃO DE EFLUENTE DE UMA CENTRAL DE PROCESSAMENTO DE ALIMENTOS VEGETAIS
}

\section{SPECIES FROM VEREDA IN PHYTOREMEDIANTION OF VEGETABLE FOOD PROCESSING UNIT EFFLUENT}

Rudmir Rogério de Camargo Faxina

Engenheiro Ambiental, Mestrando em Qualidade Ambiental/UFU. (rudcmg@gmail.com).

\section{Sueli Moura Bertolino}

Doutora em Engenharia de Materiais/UFOP. Instituto de Ciências Agrárias da Universidade Federal de Uberlândia (suelibertolino@ufu.br).

\section{Lucas Carvalho Basilio Azevedo}

Doutor em Agronomia (solos, nutrição de plantas)/ESALQ-USP. Programa de pós-graduação em Qualidade Ambiental da Universidade Federal de Uberlândia. (lucasazevedo@ufu.br).

\section{Resumo}

Este trabalho teve como objetivo avaliar o potencial da Eleocharis acutangula no tratamento do efluente de uma central de processamento de alimentos vegetais, por meio de leito cultivado em escala laboratorial. Analisou-se a influência do substrato e das plantas na remoção de DQO, sólidos totais, turbidez, nitrogênio, fósforo e estabilização do $\mathrm{pH}$. O experimento foi montado em duas caixas de vidro em casa de vegetação e teve duração de onze meses. O substrato utilizado foi cascalho de rio e apenas um dos leitos recebeu $E$. acutangula. O leito com as macrófitas reduziu 87,9\% de fósforo, 80,8\% de nitrogênio e 92,69\% de DQO em relação ao efluente bruto. Quanto ao controle, o leito experimental reduziu 54,5\% de fósforo, 33,0\% de nitrogênio e $81,4 \%$ de DQO. De acordo com os parâmetros após o tratamento em ambos os leitos, o efluente se tornou apto para disposição final, conforme os padrões da Resolução do CONAMA № 430/2011 (BRASIL, 2011) e Deliberação Conjunta COPAM-CERH № 01/2008 (MINAS GERAIS, 2008). Considerando as reduções observadas, o estudo mostrou que a espécie tem potencial no tratamento de águas residuais.

Palavras-chave: efluente industrial, leito cultivado, rizofiltração.

\section{Abstract}

The objective of this work was to evaluate the potential of the Eleocharis acutangula in the treatment of the wastewater of a central of vegetable foods processing through a laboratory scale wetland. Was analyzed the influence of the substrate and the species on the removal of COD, total solids, turbidity, nitrogen, phosphorus and $\mathrm{pH}$ stabilization. The experiment was set upin two glass boxes in a greenhouse and lasted for eleven months. The substrate used was river gravel and only one of the beds received E. acutangula. The bed with the macrophytes reduced $87.9 \%$ of phosphorus, $80.8 \%$ of nitrogen and $92.69 \%$ of COD in relation to the raw effluent. Regarding the control, the experimental bed reduced $54.5 \%$ of phosphorus, $33.0 \%$ of nitrogen and $81.4 \%$ of COD. According to the analyzed parameters, after the treatment in both beds the effluent became fit for final disposal, according to the standards of CONAMA Resolution $\mathrm{N}^{\circ}$ 430/2011 (BRASIL, 2011) and COPAM-CERH Joint Resolution N 01/2008 (MINAS GERAIS, 2008). Considering the reductions observed, the study showed that the species has potential in the treatment of wastewater.

Keywords: industrial wastewater, wetland, rhizofiltration.

\section{INTRODUÇÃO}

O crescimento no número de unidades de beneficiamento de alimentos resulta no aumento de resíduos gerados no processo. Nesse contexto, o Ministério do Meio Ambiente alerta que a disposição inadequada de suas águas residuais pode causar a contaminação do solo e dos corpos hídricos, gerando riscos ambientais que comprometem os ecossistemas locais e a saúde humana. 
Dessa forma, a caracterização dos constituintes das águas residuais é necessária para que seja possível determinar o tratamento ideal e o enquadramento nos padrões estabelecidos na legislação, visando preservar a qualidade ambiental dos ecossistemas (COSTA, 2008; METCALF; EDDY, 2014). Águas residuais de centrais de processamento de alimentos vegetais são caracterizadas pela presença de sólidos suspensos e de constituintes orgânicos, cuja maioria é de fácil biodegradabilidade, como carboidratos, proteínas e, em alguns casos, lipídios (DOBLE; KUMAR, 2005). Em geral, este tipo de efluente apresenta grande variabilidade nas concentrações de seus constituintes devido a uma série de fatores, como, por exemplo, o processo industrial empregado, a idade da indústria e a adoção de práticas conservacionistas. Tal efluente pode apresentar uma faixa de $\mathrm{DBO}_{5,20}$ de 200 a $3.000 \mathrm{mg} \mathrm{L}^{-1}$, o que representa uma carga específica de 10 a 30 kg por tonelada processada e equivale à produção de uma população de 200 a 600 habitantes por dia (von SPERLING, 2005).

A infiltração no solo e o lançamento em corpos hídricos são algumas das formas de disposição final mais utilizadas para águas residuais, devido, principalmente, à capacidade de assimilação de poluentes nestes meios. Entretanto, em função do efeito cumulativo da deposição do efluente, essas práticas exigem atenção quanto à capacidade de autodepuração do meio, para que não ocorram prejuízos à biota ou alteração da estrutura físico-química dos locais de lançamento (von SPERLING, 2005). Para tanto, o Conselho Nacional do Meio Ambiente (CONAMA), com a Resolução № 430 de 2011 (BRASIL, 2011), e o Conselho Estadual de Política Ambiental (COPAM), com a Deliberação Normativa Conjunta COPAM/CERH-MG № 01 de 2008, (MINAS GERAIS, 2008), estabelecem parâmetros para 0 lançamento de águas residuais. Os efluentes de qualquer fonte poluidora somente poderão ser lançados, direta ou indiretamente, no meio, após o devido tratamento, desde que não alterem a qualidade do receptor e obedeçam às condições, padrões e exigências dispostos nas normas supracitadas e em outras aplicáveis.

Tendo em vista este cenário, é constante a busca por métodos e tecnologias mais eficientes de tratamento de efluentes residenciais ou industriais (MARCELINO et al., 2013). São utilizadas, predominantemente, as Estações de
Tratamento de Efluentes (ETE) para águas residuais industriais. Entretanto, estas estações possuem elevado custo de implantação e manutenção, além da geração de resíduos sólidos (lodo) ao final do processo. Devido ao alto custo das estações de tratamento, algumas indústrias de pequeno porte optam por lançar águas residuais sem o tratamento adequado.

Como opção de tratamento em menor escala, existem os leitos cultivados (wetlands), também conhecidos como sistemas alagados construídos (SACs) e jardins filtrantes. Estes dispositivos combinam processos físicos, químicos e biológicos utilizando um sistema complexo de filtros naturais, composto por barreiras físicas e raízes de plantas que, em conjunto, são responsáveis por promover a segregação e purificar águas residuais (UCKER et al., 2014). Este tratamento é um tipo de fitorremediação que ganhou maior ênfase no Brasil em meados da década de 1990, como uma opção promissora e financeiramente viável (CALIJURl et al., 2009).

A ideia principal da fitorremediação é proporcionar à própria natureza a capacidade de depurar as águas contaminadas utilizando a flora e a microbiota local, evitando problemas com a introdução de espécies exóticas. A remediação do efluente ocorre, na maioria das vezes, não somente pela presença das plantas, mas também por diversos micro-organismos associados às raízes. Esta tecnologia também tem importância paisagística onde é aplicada, pois garante uma perspectiva esteticamente agradável além de trazer melhorias para o meio ambiente (TAVARES et al., 2013). Tal sistema também pode ser chamado de natural, pois se baseia na capacidade de ciclagem dos elementos contidos no efluente sem o fornecimento de qualquer fonte de energia induzida para acelerar os processos bioquímicos, os quais ocorrem de forma espontânea.

Os constituintes do sistema (substrato, vegetação e micro-organismos) têm participação direta nos processos físicos, químicos e biológicos que promovem a depuração dos efluentes nos leitos cultivados. Mesmo em diferentes configurações, estes processos ocorrem simultaneamente e, juntos, são capazes de subtrair parcelas de sólidos suspensos, compostos orgânicos solúveis, nitrogênio, fósforo, patogênicos e metais pesados (PHILIPI; SEZERINO, 2004). Estudos realizados anteriormente demonstraram bons resultados na 
remoção da carga orgânica e de compostos como nitrogênio e fósforo (PHILIPI; SEZERINO, 2004; MARTINS et al., 2007; SARNAGLIA; GONÇALVES, 2013; MONTEIRO, 2014; PANSONATO 2010).

Assim, vários tipos de leitos cultivados têm sido construídos pelo mundo, aplicando-se diferentes direções de fluxo, materiais de suporte e espécies de plantas (MARCELINO et al., 2013). Dentre as diferentes direções de fluxo, existe 0 sistema de fluxo subsuperficial que também é conhecido por filtro plantado com macrófita. Diferentemente do sistema de escoamento superficial (lâmina livre), no qual o efluente escorre gerando uma superfície sempre alagada, com odores e proliferação de mosquitos, no fluxo subsuperficial, o efluente escoa pela parte interna do leito atravessando o wetland. O fluxo pode ser subsuperficial horizontal, ou vertical, quando 0 efluente é inserido na parte superior do filtro, percola verticalmente, sendo coletado no fundo (fluxo descendente). Leitos com fluxo vertical descendente podem possibilitar uma maior taxa de transferência de oxigênio para o meio filtrante, gerando uma maior oxigenação e favorecendo a degradação aeróbia e a nitrificação (PHILIPI; SEZERINO, 2004).

Em leitos cultivados, as macrófitas agem na despoluição de corpos d'água, uma vez que suas raízes removem macronutrientes provenientes do despejo de efluentes, assimilando nitrogênio e fósforo para o crescimento e reduzindo a matéria carbonácea (ORMONDE, 2012). Também promovem estabilização da superfície do filtro, redução da velocidade do fluxo e do risco de erosão, melhora na condutividade hidráulica do solo por meio da criação de canais pelas raízes, a promoção de boas condições para o processo físico de filtração, aumento da superfície para a formação de biofilme, aeração da rizosfera e liberação de oxigênio (VYMAZAL, 2005).

Existem wetlands em funcionamento em diversas regiões do Brasil, sendo que as macrófitas mais utilizadas como agentes fitorremediadores são a Typha ssp., popularmente conhecida como Taboa, e o Papiro (Cyperus papirus) (POTT et al., 2002). Entretanto, não foram encontrados estudos relacionados com espécies de ocorrência em vereda.

A vereda é uma fitofisionomia do Cerrado que ocorre em solos hidromórficos, com áreas alagadas, favoráveis a ocorrência de macrófitas, circundadas por campo limpo, com predominância de uma vegetação herbáceo- graminosa e outra arbóreo-arbustiva (RIBEIRO; WALTER, 2008).

Há muitos anos, recomendam-se testes com novas espécies que cresçam bem no efluente e no clima local (POTT et al., 2002). No presente trabalho, a espécie vegetal selecionada foi a Eleocharis acutangula (Roxb.) Schult, uma macrófita de ampla ocorrência, com base em levantamento e visitas a campo em áreas alagadas de vereda. Outras espécies do mesmo gênero já foram utilizadas como fitorremediadores em tratamento de águas residuais, embora nada se conheça sobre 0 potencial da espécie selecionada. A Eleocharis acutangula, da família Cyperaceae Juss - Eleocharis $R$. Br., foi a espécie com maior cobertura e frequência relativa de exemplares, tanto na estação chuvosa quanto na estação de seca, observados em uma lagoa associada à vereda, na região de Terenos/MS, em levantamento realizado por Moreira et al. (2011).

Foi levantada a hipótese de que o cultivo em leito de uma macrófita com ocorrência em vereda é eficiente para a melhora dos parâmetros de qualidade de um efluente industrial, permitindo a disposição final conforme a legislação vigente. Portanto, o objetivo deste trabalho foi caracterizar um efluente industrial proveniente de uma central de processamento de alimentos vegetais, e avaliar o potencial desta macrófita como agente fitorremediador em seu tratamento. Este estudo é relevante porque pode oferecer subsídios para a utilização de novas espécies e da técnica de fitorremediação como forma de tratamento desse tipo de efluente.

\section{MATERIAIS E MÉTODOS}

\section{1 Área de estudo}

A pesquisa foi realizada no Campus Glória da Universidade Federal de Uberlândia (UFU), localizada no Município de Uberlândia/MG (Figura 1), onde o clima predominante, segundo a classificação de Köppen, é do tipo tropical quente úmido (Aw), com inverno seco e verão chuvoso; a precipitação média anual fica entre 1.500 e 1.600 $\mathrm{mm}$ e a temperatura média em torno de $23^{\circ} \mathrm{C}$ (SILVA et al., 2003). O relevo é suavemente ondulado sobre formações sedimentares e o solo predominante é o Latossolo Vermelho Distrófico (LVd), sendo ácido e pouco fértil (BRITO et al., 2003; EMBRAPA/EPAMIG, 1982). A vegetação predominante é característica das fitofisionomias de Cerrado. O Campus Glória - UFU possui uma 
área total de 291 hectares e está inserida na

afluente à margem direita do Rio Uberabinha.

Bacia Hidrográfica do Córrego do Glória que é um

\section{Figura 1 - Localização da central de processamento de alimentos que gera o efluente no Campus Glória}

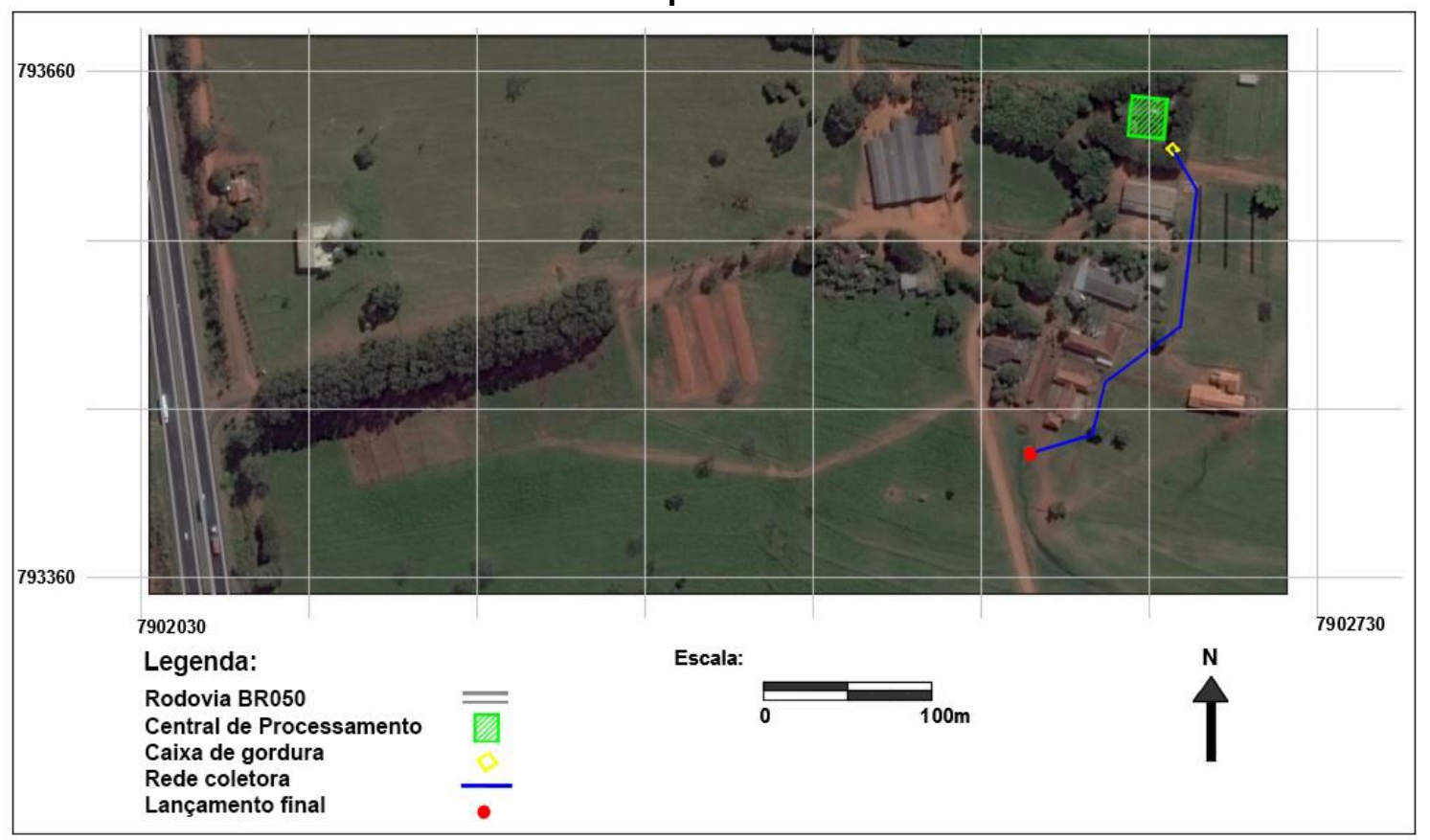

Fonte: Imagem do satélite Quick Bird 2007, composição e imagem do Google Earth de 12/06/2010, adaptado em 01/12/2016, coordenadas UTM.

\subsection{Origem do efluente}

Na Fazenda Experimental do Campus Glória, há uma central de processamento de alimentos vegetais, com horário de funcionamento de segunda-feira à sexta-feira das $07 \mathrm{~h}$ às $16 \mathrm{~h}$, com uma hora de intervalo, na qual trabalham onze funcionários. Nela, são processados, em média, $1.000 \mathrm{~kg}$ por dia de alimentos de origem vegetal, sendo principalmente verduras folhosas, além de legumes e algumas frutas para atendimento aos restaurantes universitários da UFU.

As etapas do processamento são divididas em: enxágue primário, higienização química, enxágue secundário, separação, preparação (moagem quando necessário), pesagem, embalagem e acondicionamento (câmara fria). Os resíduos sólidos orgânicos gerados no processo são reaproveitados e utilizados na suplementação animal da própria fazenda. Os banheiros existentes nas dependências possuem captação com fossas e sumidouros individuais, ou seja, não ocorre contato de águas cinzas com o efluente industrial.

Toda a água utilizada na central de processamento é captada por meio de poço artesiano com bombeamento, armazenada em reservatório e distribuída por gravidade. Atualmente, são utilizados, em média, 2.750 a 3.250 litros de água potável por dia somente na central de processamento de alimentos, em períodos de produção normal. A higienização dos alimentos é feita a partir de quatro caixas d'água, sendo duas de 1.000 litros cada na etapa inicial. Nesta etapa, a primeira caixa d'água é destinada para a limpeza e enxágue primário, apenas com água; na segunda caixa, é realizada a higienização dos vegetais com adição de dicloroisocianurato de sódio $\left(2 \mathrm{gL}^{-1}\right)$. Na segunda etapa, é realizado um novo enxágue conforme o tipo de vegetal selecionado, com a utilização das outras duas caixas d'água, uma de 500 litros e outra de 50 litros, dependendo da quantidade que está sendo processada. Ainda há o consumo de água para a higienização das estruturas antes de iniciarem as atividades e para limpeza ao final do expediente. Tais procedimentos utilizam adições de produto de limpeza à base de hidróxido de sódio e de detergente desincrustante alcalino (diluição de 15\% para 1 litro de água). Também é utilizado etanol $70 \%$ para a desinfecção das bancadas. Toda água usada é completamente revertida em efluente ao final do processo, e o consumo pode variar conforme a produção em 
diferentes épocas do ano e conforme os alimentos processados, podendo ultrapassar 4.750 litros por dia.

A variabilidade do consumo de água na central de processamento, em função da quantidade de alimentos processados por dia, encontra-se dentro da faixa de volume médio específico levantado por von Sperling (2005), para indústrias alimentícias do tipo de frutas e legumes em conservas (4-50 $\left.\mathrm{m}^{3} \mathrm{ton}^{-1}\right)$.

A destinação final deste efluente industrial é feita atualmente através de infiltração no solo, por meio do lançando em área de pastagem localizada a duzentos metros abaixo da central de processamento, por intermédio de uma rede coletora e diferença de cotas no terreno. A única etapa de pré-tratamento existente é uma caixa de separadora em concreto, que é responsável pela separação e retenção dos resíduos sólidos maiores, segregados ao efluente líquido. A limpeza desta é realizada com periodicidade mensal e os resíduos removidos são utilizados como adubo nos jardins adjacentes.

\subsection{Caracterização do efluente}

A coleta das amostras do efluente industrial e a realização das análises físico-químicas (Tabela 1) para caracterização inicial ocorreram nos dois primeiros meses do experimento. Durante esse período, foram analisados dez parâmetros. A coleta das amostras foi realizada em um ponto após a passagem pela caixa separadora existente no local.

Tabela 1 - Parâmetros analisados e métodos para a caracterização do efluente de uma central de abastecimento de alimentos vegetais

\begin{tabular}{ccc}
\hline Parâmetros & Metodologias & Unidades \\
\hline Temperatura & Direto - termômetro de mercúrio & ${ }^{\circ} \mathrm{C}$ \\
pH & Sonda HACH PHC 10101 & - \\
Condutividade elétrica & Sonda HACH CDC 40101 & $\mu \mathrm{cm}^{-1}$ \\
Cor & Colorímetro Poli Control Aqua Color & $\mathrm{uC}$ \\
Turbidez & Turbidímetro Poli Control AP2000 & $\mathrm{NTU}$ \\
$\mathrm{DQO}$ & Refluxo Fechado - (APHA, 2012) & $\mathrm{mgL}^{-1}$ \\
DBO5,20 & Método Manométrico - (APHA, 2012) & $\mathrm{mgL}^{-1}$ \\
Fósforo (PO $\left.4^{3-}\right)$ & Método Colorimétrico do Ácido & $\mathrm{mgL}^{-1}$ \\
Sólidos totais & Vanadomolibdofosfórico - (APHA, 2012) & $\mathrm{mgL}^{-1}$ \\
Nitrogênio (NTK) & Método Gravimétrico - (APHA, 2012) & $\mathrm{mgL}^{-1}$ \\
\hline
\end{tabular}

Fonte: Dados da pesquisa.

Para as análises, coletaram-se $1.500 \mathrm{~mL}$ do efluente industrial em cada amostragem, semanalmente, às sextas-feiras no período matutino, totalizando seis amostragens nomeadas sequencialmente de A, B, C, D, E e F. Todas as coletas foram efetuadas seguindo as orientações dispostas nas NBR/ABNT 9.897/1997 e NBR/ABNT 9.898/1997 (ABNT, 1987a; 1987b).

O parâmetro de temperatura foi aferido no momento da coleta, para que não houvesse interferência no resultado até a chegada ao laboratório. As análises dos demais parâmetros foram realizadas no Laboratório de Qualidade Ambiental - LAQUA (UFU).

A caracterização do efluente industrial da central de processamento de alimentos foi representada por meio de análises em duplicada, para o parâmetro de nitrogênio total, e em triplicata, para os demais parâmetros de cada amostragem.

\subsection{Construção dos leitos}

Em relação ao dimensionamento de leitos cultivados, existem diversas formas, as quais são adotadas dependendo do tipo do efluente e do clima (HOFFMANN et al., 2011). Foram utilizadas para este estudo duas caixas de vidro idênticas com capacidade máxima para 28 litros, organizadas em casa de vegetação no Campus Umuarama da Universidade Federal de Uberlândia - UFU.

A montagem das caixas teve início logo após o período de caracterização. Usaram-se placas de vidro de $0,6 \mathrm{~cm}$ de espessura na base e 0,5 $\mathrm{cm}$ nas laterais, sendo $40 \mathrm{~cm}$ de comprimento, 20 $\mathrm{cm}$ de largura e $35 \mathrm{~cm}$ de altura, e ambas com 
um registro de $1 / 2$ " a $2 \mathrm{~cm}$ da base em uma das laterais. Uma caixa foi utilizada para o "Leito Controle", sem plantas, e a segunda para o "Leito Experimental", com a macrófita.

Após a montagem dos leitos, realizou-se a composição do sistema filtrante em duas camadas com cascalho de rio lavado (grânulos) em diferentes granulometrias, devido às suas características e capacidade de filtragem. A primeira camada foi configurada com $7 \mathrm{~cm}$ de cascalho fino $(\varnothing=2-3 \mathrm{~mm})$ na base, sobreposta por outra de $23 \mathrm{~cm}$ de cascalho grosso $(\varnothing=4-6$ $\mathrm{mm}$ ), totalizando $30 \mathrm{~cm}$ de altura e garantindo um volume útil de 6,5 litros em cada leito.

A altura das camadas do sistema filtrante, a área superficial e, consequentemente, o volume útil dos leitos foram definidos com base nos resultados do estudo de caracterização inicial do efluente industrial gerado na central de processamento de alimentos da Fazenda do Glória.

Para compor a camada viva do sistema, como agente fitorremediador no leito experimental, foram adquiridos, em loja especializada no comércio de macrófitas e de equipamentos para aquicultura, aproximadamente, 100 exemplares de $E$. acutangula.

\subsection{Operação dos leitos}

A operação teve início com o plantio das macrófitas no leito experimental (Figura 2). Concomitantemente, o leito foi preenchido apenas com água de abastecimento para estimular 0 desenvolvimento das raízes das plantas ao longo da camada superior de cascalho. Esse período de adaptação teve duração de dois meses, com monitoramento e trocas de água semanais.

Após o período de adaptação das espécies no leito experimental, foi iniciada a operação do experimento com regime de batelada, dividida em oito etapas (Figura 3). O tempo de detenção hidráulica foi fixado em três dias, pois intervalos de 3 a 7 são apontados como ideais para 0 tratamento (MOREL; DIENER, 2006).

$\mathrm{Na}$ etapa de coleta do efluente bruto para introdução nos leitos, foram amostrados 15 litros no mesmo ponto após a passagem pela caixa separadora. Deste montante, 13 litros foram destinados para os leitos, sendo 6,5 litros em cada e o restante utilizado para as análises do efluente bruto.

\section{Figura 2 - Leito Experimental e Leito Controle para tratamento do efluente da central de processamento de alimentos vegetais}

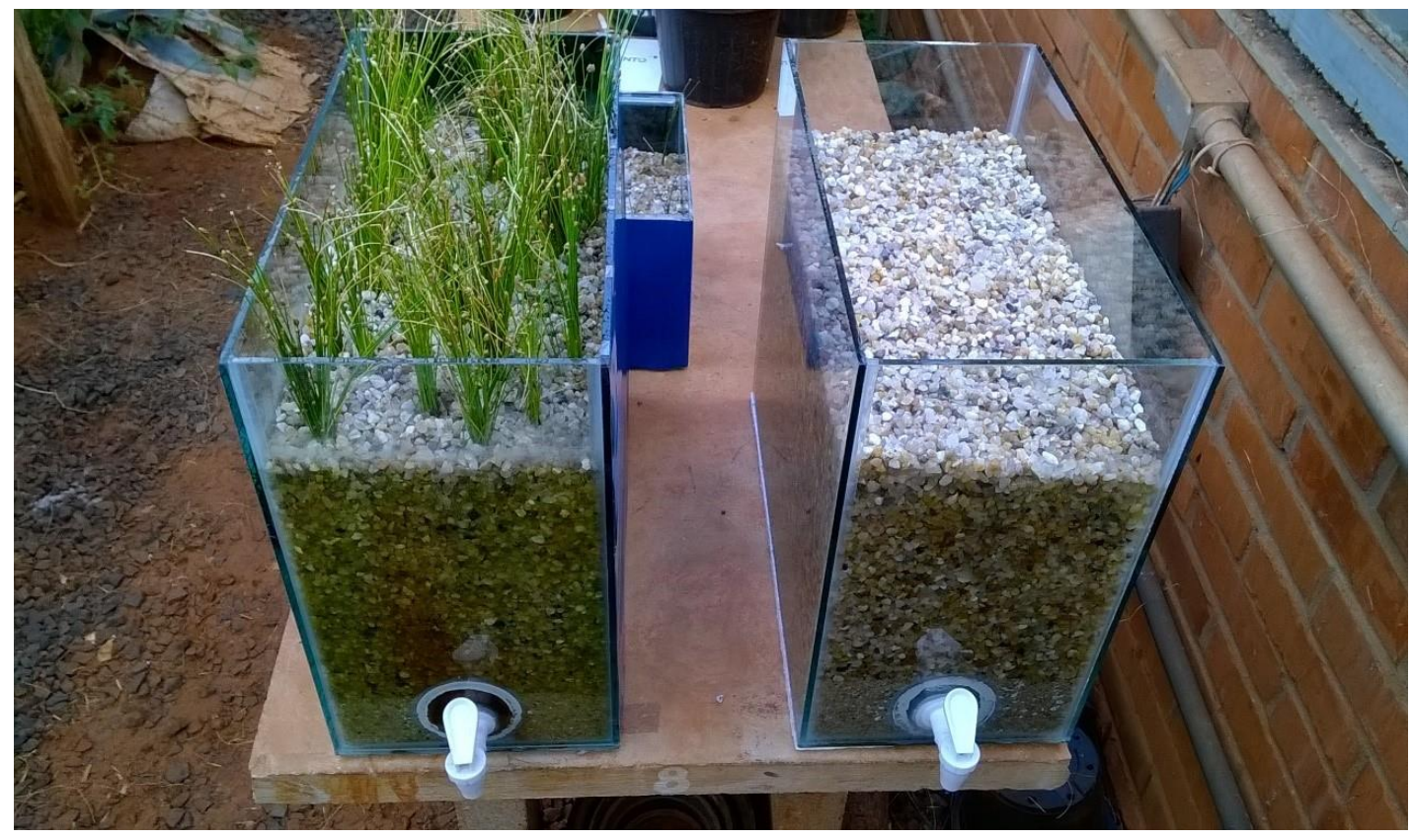

Fonte: Autoria própria.

Após a execução das oito etapas de operação (Figura 3), o leito experimental foi mantido em repouso por alguns dias antes do início de um novo procedimento. O experimento foi acompanhado por 180 dias, com um total de nove repetições.

Para melhor avaliar o desempenho do sistema, ou seja, a capacidade de filtro e 
depuração ao longo do tempo, analisaram-se, em cada ciclo de operação, os parâmetros de $\mathrm{pH}$, sólidos totais, turbidez, fósforo $\left(\mathrm{PO}_{4}^{3-}\right)$, nitrogênio (NTK) e demanda química de oxigênio (DQO), conforme métodos descritos na Tabela 1. Todas as análises foram em triplicata, exceto para nitrogênio (NTK) que foi em duplicata.

A eficiência e o desempenho do sistema de tratamento foram obtidos com a comparação entre os valores dos parâmetros do efluente industrial bruto, analisados antes da introdução no sistema, e os valores dos mesmos parâmetros após o intervalo de tempo definido.
Os dados da caracterização inicial submeteram-se à análise estatística descritiva e teste de hipótese para as médias. Anteriormente à análise de variância (ANOVA), os dados foram submetidos à análise de normalidade e homogeneidade da variância por meio do programa Minitab 17. Para normalização dos dados, os valores de nitrogênio (NTK) foram transformados como $(x+0,5)^{0,5}$ e os de fósforo como $1 / x^{0,5}$. As médias foram comparadas pelo teste de Scott-knott, por meio do programa Sisvar (FERREIRA, 2011), versão 5.6, e os tratamentos foram considerados significativos para $p<0,05$.

\section{Figura 3 - Fluxograma das etapas de operação dos leitos para tratamento do efluente da central de processamento de alimentos}

Coleta do efluente bruto na central de processamento de alimentos
Análises das amostras de efluente tratado coletadas em cada leito
Fonte: Autoria própria.

\section{RESULTADOS E DISCUSSÃO}

\subsection{Caracterização do efluente}

As características físico-químicas, o volume e a concentração dos efluentes industriais variam conforme o tipo de indústria, tipo de processo de fabricação, o período de operação, a matériaprima e os métodos de controle de resíduos (von SPERLING, 2005). Ocorreram variações nos resultados entre todas as amostragens (Tabela 2), uma vez que as características deste efluente oscilaram conforme os alimentos que foram preparados diariamente na central de processamento, devido às configurações dos cardápios ofertados nos restaurantes universitários da UFU.

A temperatura média foi de $25,7 \stackrel{\circ}{ } \mathrm{C}$, o que está em concordância com a temperatura média do primeiro trimestre do ano, entre $25^{\circ} \mathrm{C}$ e $26^{\circ} \mathrm{C}$ na região do Triângulo Mineiro, segundo dados da Normal Climatológica (1961-1990) do INMET
(2016). Conforme a Resolução CONAMA № 430 de 2011, a temperatura do efluente deve ser inferior a $40^{\circ} \mathrm{C}$ e o lançamento deste não deve exceder em $3{ }^{\circ} \mathrm{C}$ a temperatura do corpo receptor (BRASIL, 2011).

$\mathrm{O} \mathrm{pH}$ indica o caráter ácido ou básico e, indiretamente, a produção de ácidos (fermentação) por micro-organismos no efluente e estimulados por matéria orgânica em abundância, como é o caso de efluentes industriais do processamento de alimentos. $\mathrm{O}$ menor valor de $\mathrm{pH}$ encontrado foi 4,70 . Este $\mathrm{pH}$ levemente mais ácido pode ter sido influenciado pelas características do efluente no dia da coleta e pelos alimentos processados anteriormente. A média dos valores de $\mathrm{pH}$ foi de 5,17 , e encontrase fora da faixa estabelecida pela Deliberação Normativa Conjunta № 01 do COPAM-CERH de 2008, que indica um $\mathrm{pH}$ de 6,0 a 9,0 para 0 padrão de lançamento de efluentes (MINAS GERAIS, 2008). As condições estabelecidas pela 
Normativa são mais rigorosas do que os padrões da Resolução CONAMA № 430 (BRASIL, 2011) ( $\mathrm{pH}$ de 5,0 a 9,0).

A condutividade elétrica está diretamente relacionada com as substâncias dissolvidas no efluente. Este parâmetro afere indiretamente a quantidade de matéria inorgânica passível de se solubilizar à fração aquosa do meio. O maior valor analisado foi $768 \mu \mathrm{scm}^{-1}$. Porém, a Resolução CONAMA № 430 de 2011 e a Deliberação Normativa Conjunta № 01 do COPAM-CERH de 2008 não estabelecem valores limites para condutividade elétrica.

Tabela 2 - Valores de média, desvio padrão, mínimo, máximo e coeficiente de variação por parâmetro referente à caracterização inicial do efluente da central de processamento de alimentos

\begin{tabular}{|c|c|c|c|c|c|c|}
\hline Parâmetro & Unidade & Média & $\begin{array}{c}\text { Desvio } \\
\text { Padrão ( } \pm \text { ) }\end{array}$ & Mínimo & Máximo & $\begin{array}{l}\text { Coeficiente de } \\
\text { Variacão (\%) }\end{array}$ \\
\hline Temperatura & ${ }^{\circ} \mathrm{C}$ & 25,7 & 1,79 & 23,8 & 28,8 & 6,98 \\
\hline $\mathrm{pH}$ & - & 5,17 & 0,39 & 4,7 & 5,99 & 7,49 \\
\hline Condutividade elétrica & $\mu \mathrm{scm}^{-1}$ & 493,22 & 157,63 & 260 & 768 & 31,96 \\
\hline Cor & $\mathrm{uC}$ & 175,58 & 95,81 & 29,44 & 294 & 54,57 \\
\hline Turbidez & NTU & 45,88 & 28,78 & 11,48 & 88,8 & 62,73 \\
\hline Sólidos totais & $\mathrm{mgL}^{-1}$ & 747,44 & 399,96 & 293,4 & 1.448 & 53,51 \\
\hline DQO & $\mathrm{mgL}^{-1}$ & 712,88 & 332,78 & 156,81 & $1.054,5$ & 46,68 \\
\hline $\mathrm{DBO}_{5,20}$ & $\mathrm{mgL}^{-1}$ & 503,97 & 347,55 & 50,55 & $1.127,99$ & 68,96 \\
\hline Nitrogênio (NTK) & $\mathrm{mgL}^{-1}$ & 6,63 & 7,56 & 1,34 & 25,7 & 114,08 \\
\hline Fósforo $\left(\mathrm{PO}_{4}^{3-}\right)$ & $\mathrm{mgL}^{-1}$ & 2,72 & 1,75 & 0,57 & 6,3 & 64,19 \\
\hline
\end{tabular}

Fonte: Dados da pesquisa.

A coloração é provocada pela presença de determinadas substâncias dissolvidas (ferro, manganês, corantes naturais ou artificiais). Assim, sugere-se que a variação desse parâmetro entre as amostragens seja devido às características do alimento processado, incluindo subprodutos de biodegradação da carga orgânica. A média dos valores obtidos nas amostragens foi de 170,02 Uc, o que confere potencial capaz de alterar o valor máximo permitido no corpo receptor, dependendo das suas características e classificação (CONAMA, № 357 de 2005) (BRASIL, 2005).

Com relação ao parâmetro de turbidez, o qual indica indiretamente a presença de substâncias em suspensão no efluente líquido, 0 maior valor de turbidez foi 88,80 NTU, possivelmente devido à maior presença de argila e silte que estavam aderidos aos vegetais processados. A média de turbidez foi de 45,88 NTU, o que confere potencial ao efluente para alterar o valor máximo permitido no corpo receptor, dependendo das suas características e classificação (CONAMA № 357 de 2005) (BRASIL, 2005).

O parâmetro de sólidos totais (ST) é composto por substâncias, em suspensão e dissolvidas, de composição orgânica e/ou inorgânica. O menor valor de ST foi de $293,4 \mathrm{mg}$
$\mathrm{L}^{-1}$ e o maior, de $1.448 \mathrm{mg} \mathrm{L}^{-1}$. Existe uma correlação linear entre os resultados de turbidez $e$ sólidos totais ( $\left.R^{2} 88,11 \%\right)$ (Figura 4$)$, indicando que o parâmetro de sólidos totais do efluente industrial da central de processamento é constituído, principalmente, por sólidos suspensos. Portanto, essa correlação sugere que, em todas as amostragens, o parâmetro de sólidos suspensos totais estará em desacordo com o estabelecido pela Deliberação Normativa Conjunta № 01 do COPAM-CERH de 2008, que é de $100 \mathrm{mg} \mathrm{L}^{-1}$ (MINAS GERAIS, 2008).

Em relação à $D Q O$, o menor valor foi de $156,81 \mathrm{mgL}^{-1}$ e o maior valor, de $1.054,5 \mathrm{mgL}^{-1}$; enquanto que para 0 parâmetro de $\mathrm{DBO}_{5,20}$, o menor valor foi $50,55 \mathrm{mgL}^{-1} \mathrm{e}$ o maior foi $1.127,99$ $\mathrm{mgL}^{-1}$. Também é possível observar uma variação nos valores médios obtidos para a DQO $(712,88$ $\left.\mathrm{mgL}^{-1}\right)$ e a $\mathrm{DBO}_{5,20,}\left(503,97 \mathrm{mgL}^{-1}\right)$, corroborando com os valores observados por von Sperling (2005). Essa variação pode ser justificada quando comparada com sólidos totais, uma vez que a DQO inclui partículas orgânicas em suspensão na massa líquida. Além disso, as variações dos alimentos processados contribuíram para a oscilação dos resultados.

Para efluentes industriais, conforme estabelecido na Resolução CONAMA № 430 de 2011, é necessário um tratamento cuja remoção 
mínima seja de $60 \%$ de $\mathrm{DBO}_{5,20}$ ou valor mediante estudo de autodepuração do corpo receptor (BRASIL, 2011). Como não existe tratamento da água residual em questão ou estudo de autodepuração do solo no local de lançamento, o tratamento adequado deve ser capaz de remover, pelo menos, $302,38 \mathrm{mgL}^{-1}(60 \%)$ do valor médio obtido para $\mathrm{DBO}_{5,20}$

Figura 4 - Gráfico de correlação entre os parâmetros de turbidez e sólidos totais

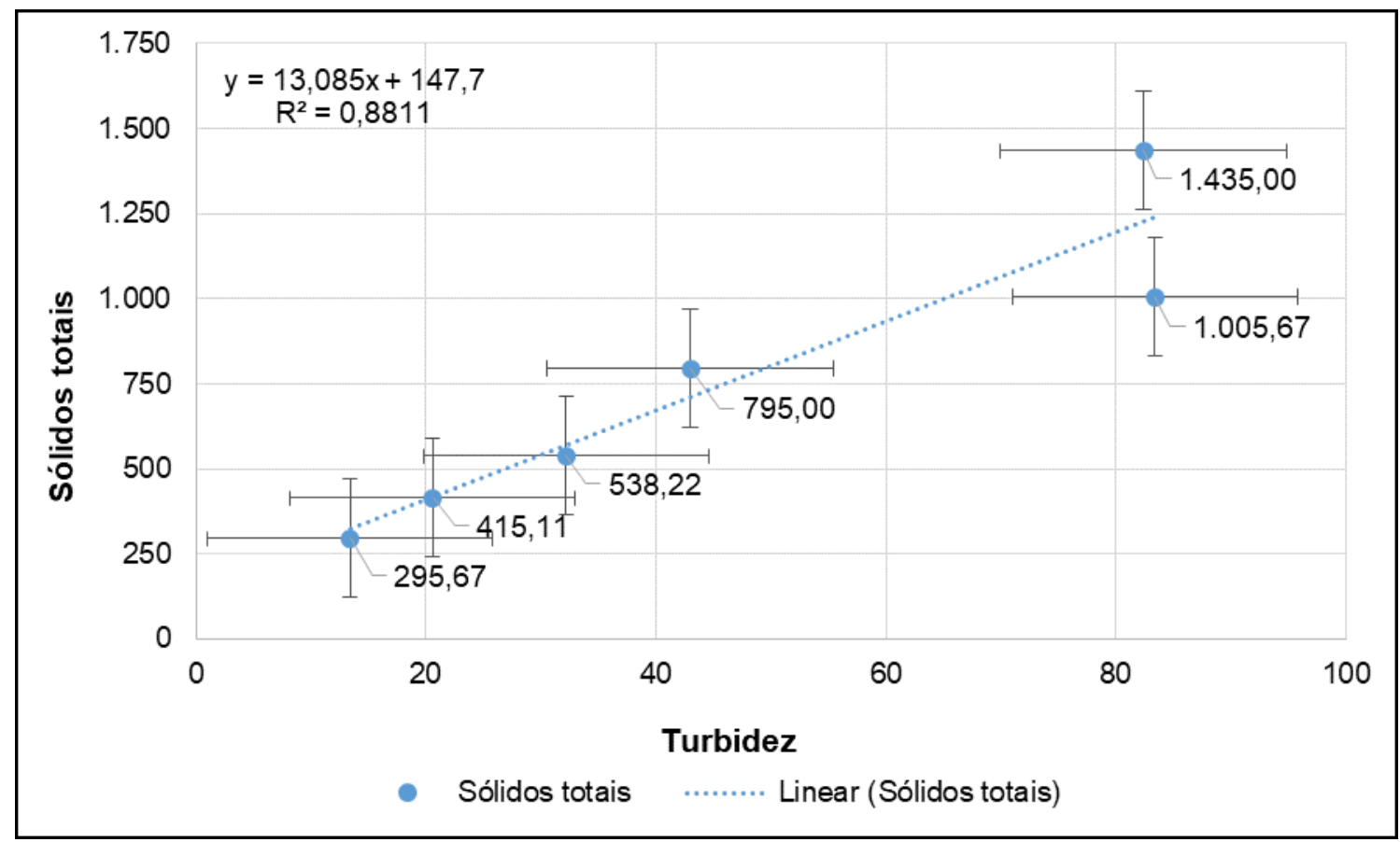

Fonte: Autoria própria.

O valor da relação das médias de $\mathrm{DQO} / \mathrm{DBO}_{5,20}$ foi de 1,41 . Conforme relatado por Braile e Cavalcanti (1993), quanto menor for a relação $\mathrm{DQO} / \mathrm{DBO}_{5,20}(<2,5)$, mais elevada é a fração biodegradável do efluente. Ainda segundo esses autores, se a média de tal relação for inferior a 2,5, indica-se um tratamento biológico.

A relação $\mathrm{DQO} / \mathrm{DBO}_{5,20}$ varia também à medida que 0 efluente passa pela caixa separadora da central de processamento de alimentos (tratamento físico). Conforme mencionado por von Sperling (2005), a tendência para a relação é de aumentar, devido à redução da fração biodegradável pelo tratamento, ao passo que a fração inerte permanece aproximadamente inalterada.

O nitrogênio é um componente importante em termos de geração e controle da poluição dos corpos receptores devido a alguns aspectos, como o favorecimento ao crescimento de algas e micro-organismos e na conversão da amônia a nitrito e este a nitrato (nitrificação), consumindo oxigênio dissolvido. O Nitrogênio total Kjeldahl (NTK) engloba as frações amônia e nitrogênio orgânico que são as predominantes nos esgotos domésticos brutos (von SPERLING, 2005). Como a média dos valores encontrados para $\mathrm{pH}$ no efluente da central de processamento é inferior a 8,0 , praticamente toda a amônia presente está na forma de $\mathrm{NH}_{4}^{+}$.

O NTK teve valores máximos de $25,70 \mathrm{mg} \mathrm{L}^{-}$ ${ }^{1}$ e mínimos de $1,34 \mathrm{mg} \mathrm{L}^{-1}$. Estes dados refletem uma grande variabilidade nas concentrações de nitrogênio no efluente da central de processamento de alimentos. A Resolução CONAMA № 430 (BRASIL, 2011) não estabelece valores limites para nitrogênio total, apenas para nitrogênio amoniacal total $\left(20,0 \mathrm{mg} \mathrm{L}^{-1}\right)$ e outros compostos derivados.

O fósforo é outro componente importante, também associado ao crescimento de algas e micro-organismos que são responsáveis pela estabilização da matéria orgânica. Os ortofosfatos são diretamente disponíveis para o metabolismo biológico, e o despejo industrial é uma das principais fontes (von SPERLING, 2005). O valor mínimo de fósforo $\left(\mathrm{PO}_{4}^{3-}\right)$ foi de $0,57 \mathrm{mg} \mathrm{L}^{-1-}$, e o máximo de $6,3 \mathrm{mg} \mathrm{L}^{-1}$. Estes valores indicam certa variabilidade nas concentrações do efluente. A Deliberação Normativa Conjunta № 01 do COPAM-CERH de 2008 não estabelece valores limites para fósforo total, apenas padrões conforme as classes dos cursos d'água, em que a maior concentração de fósforo total $\left(0,15 \mathrm{mg} \mathrm{L}^{-1}\right)$ 
é para ambiente lótico de água doce classe 3 (MINAS GERAIS, 2008).

Com base nas concentrações de fósforo e nitrogênio encontradas, o maior problema para o solo no local de lançamento final é o volume do efluente e não especificamente as concentrações de $\mathrm{P}$ e N.

A relação $C: N: P$, levantada a partir dos valores médios de DQO, Nitrogênio (NTK) e fósforo $\left(\mathrm{PO}_{4}{ }^{3-}\right.$ ), foi de 101:0,95:0,4, enquanto que a relação ideal para métodos de tratamento por processos biológicos para efluentes industriais é de 100:5:1 (RUSSELL, 2006). Portanto, a relação $\mathrm{C}: \mathrm{N}: \mathrm{P}$ encontrada sugere que, para um possível tratamento biológico, haverá uma limitação de nitrogênio para 0 crescimento dos microorganismos responsáveis pela decomposição da matéria orgânica.

Com base na caracterização inicial do efluente industrial bruto da central de processamento de alimentos, foi possível definir os valores de projeto (área superficial, altura das camadas do substrato e volume útil), para a construção dos leitos de tratamento. $\mathrm{Na}$ elaboração do projeto dos leitos, considerando a concentração média de $\mathrm{DBO}_{5,20}$ de $503,97 \mathrm{mg} \mathrm{L}^{-1}$, o volume útil de $6,5 \mathrm{~L}$ e 0 tempo de detenção hidráulica (TDH) de 3 dias, obteve-se uma carga orgânica média aplicada de $13,65 \mathrm{~g} \mathrm{DBOm}^{-2} \mathrm{dia}^{-1}$ em cada leito, valor que está dentro da faixa recomendada por Morel e Diener (2006).

\subsection{Operação dos leitos}

A média do $\mathrm{pH}$ do efluente bruto da central de processamento de alimentos, durante 0 período de acompanhamento dos leitos, foi 4,45 (Tabela 3). Esse valor mais ácido pode estar relacionado à abundância de matéria orgânica, à produção de ácidos orgânicos por bactérias e à fermentação na etapa de tratamento inicial (caixa separadora) da central de processamento de alimentos (PHILIPI; SEZERINO, 2004).

Os leitos atuaram como tanques estabilizadores de $\mathrm{pH}$, pois a acidez do efluente bruto foi neutralizada para valores acima de 6,5, em ambos os leitos de tratamento (Tabela $3 \mathrm{e}$ Figura 5). Isso pode ter ocorrido devido à produção de íons bicarbonato $\left(\mathrm{HCO}^{3-}\right)$ derivados da etapa de acetogênese do processo de digestão anaeróbica (AQUINO, 2005).

A presença de sólidos no efluente industrial da central de processamento de alimentos vegetais está, provavelmente, relacionada com as impurezas, partículas de solo e pequenos fragmentos dos alimentos, extraídos e liberados durante 0 processo de higienização, conforme mencionado anteriormente. Observa-se um maior desvio padrão nas amostras do efluente bruto, o que indica uma maior oscilação nas concentrações, acompanhando a variação e quantidades de alimentos processados. Os sólidos totais foram menores após os tratamentos nos leitos controle $\left(399,17 \mathrm{mgL}^{-1}\right)$ e experimental (334,33 $\left.\mathrm{mgL}^{-1}\right)$ em relação ao efluente bruto (715,78 $\mathrm{mgL}^{-1}$ ) (Tabela 3). No efluente tratado no leito controle, verificou-se uma remoção superior a $44 \%$, enquanto que, no leito experimental, a taxa de remoção ultrapassou 53\% (Figura 6). A remoção de sólidos suspensos nos leitos é feita, principalmente, pela sedimentação, decomposição e incorporação ao biofilme simultaneamente (PHILIPI; SEZERINO, 2004). Em um estudo realizado por Monteiro (2014), para tratamento de efluente de um escritório com wetland construído com fluxo vertical, o autor obteve uma eficiência média de $93 \%$ na remoção de sólidos suspensos. Pansonato (2010) obteve cerca de $80 \%$ de remoção do mesmo parâmetro em um sistema semelhante.

Tabela 3 - Valores médios, desvio padrão e diferença estatística por parâmetro quanto à origem do efluente gerado na central de processamento de alimentos

\begin{tabular}{|c|c|c|c|c|}
\hline Parâmetro & Unidade & Efluente Bruto & $\begin{array}{c}\text { Tratado Leito } \\
\text { Controle }\end{array}$ & $\begin{array}{l}\text { Tratado Leito } \\
\text { Experimental }\end{array}$ \\
\hline $\mathrm{pH}$ & - & $4,45 \pm 0,3(b)$ & $6,66 \pm 0,3(a)$ & $6,55 \pm 0,3(a)$ \\
\hline Sólidos totais & $\mathrm{mgL}^{-1}$ & $715,78 \pm 316,2(b)$ & $399,17 \pm 96,7$ (a) & $334,33 \pm 66,6$ (a) \\
\hline Turbidez & NTU & $40,89 \pm 32,4(b)$ & $4,51 \pm 2,9(a)$ & $5,25 \pm 1,5(a)$ \\
\hline Fósforo $\left(\mathrm{PO}_{4}^{3-}\right)$ & $\mathrm{mgL}^{-1}$ & $0,83 \pm 0,4$ (c) & $0,22 \pm 0,1(b)$ & $0,1 \pm 0(\mathrm{a})$ \\
\hline Nitrogênio (NTK) & $\mathrm{mgL}^{-1}$ & $3,7 \pm 0,7$ (c) & $1,06 \pm 0,1$ (b) & $0,71 \pm 0,2(a)$ \\
\hline DQO & $\mathrm{mgL}^{-1}$ & $479,81 \pm 95,2$ (c) & $188,97 \pm 34,9(b)$ & $35,07 \pm 9,3(a)$ \\
\hline
\end{tabular}

Fonte: Dados da pesquisa. 
Figura 5 - Valores de pH e desvio padrão do efluente bruto da central de processamento de alimentos e dos tratados no leito controle e experimental cultivado com $E$. acutangula

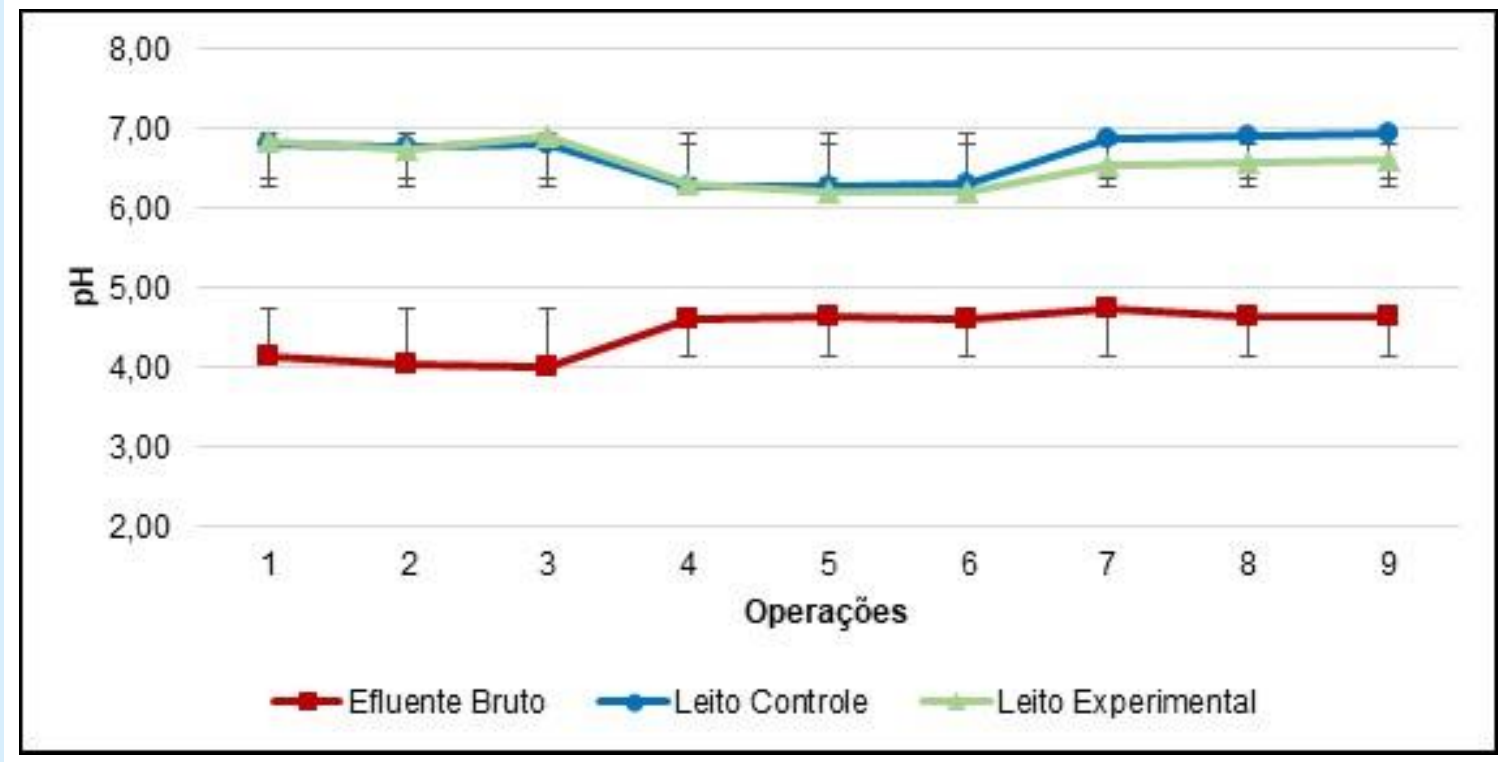

Fonte: Autoria própria.

Figura 6 - Valores de eficiência dos parâmetros de sólidos totais, turbidez, fósforo, nitrogênio (NTK) e DQO do efluente tratado nos leitos controle e experimental

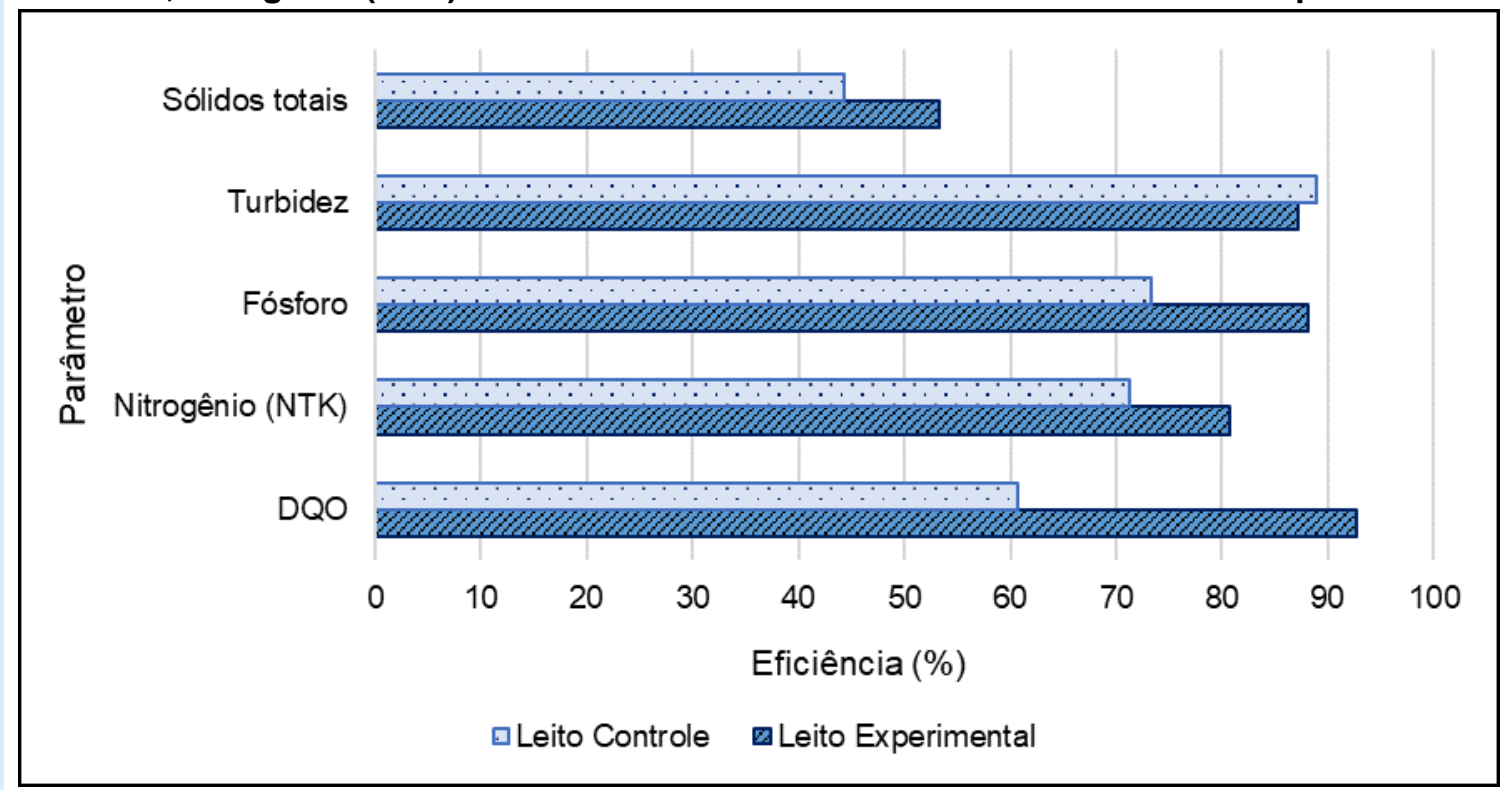

Fonte: Autoria própria.

Assim como para $\mathrm{pH}$ e sólidos totais, a turbidez foi reduzida nos leitos, independente da presença de plantas, em comparação com 0 efluente bruto (Tabela 3). Após a passagem pelos leitos, obteve-se uma eficiência superior a $87 \%$ na remoção deste parâmetro (Figura 6). Tal valor corrobora com os estudos de Pansonato (2010) e Gonçalves (2009), os quais relataram uma eficiência próxima de $70 \%$ na remoção de turbidez. Esta foi reduzida nos leitos, provavelmente, devido à redução de sólidos suspensos, como pode ser vista pela relação entre sólidos totais e turbidez (Figura 4).

O leito cultivado com Eleocharis acutangula reduziu, significativamente, os valores de fósforo, nitrogênio e DQO em relação ao leito controle e ao efluente bruto. Após a passagem pelo leito experimental, a média do teor de fósforo foi de $0,1 \mathrm{mgL}^{-1}$, o que representa uma redução de $87,9 \%$ em relação ao efluente bruto, e $54,5 \%$ quando comparado com o leito controle (Figura 6). Esses valores são superiores a outros estudos 
com leito cultivado: Monteiro (2014) obteve redução de $75 \%$ na remoção de fósforo na forma ortofosfato, enquanto que Pansonato (2010) obteve apenas $33 \%$ de remoção em um wetland vertical. A remoção de fósforo em leitos cultivados ocorre pela precipitação química, adsorção, assimilação dos vegetais e biofilmes formados no substrato e no sistema radicular (SOUSA et al., 2004). No entanto, a presença de E. acutangula promoveu uma maior redução que pode ter sido ocasionada pela absorção de fósforo para seu metabolismo.

O teor de nitrogênio no efluente da central de processamento de alimentos é baixo, pois não ocorre mistura com substâncias ricas nesse elemento químico, como urina, a principal fonte em efluentes domésticos (GONÇALVES, 2009). Portanto, o baixo teor de nitrogênio presente neste efluente pode ser proveniente dos processos de higienização dos alimentos, visto que a média para 0 efluente bruto foi de 3,70 $\mathrm{mgL}^{-1}$. Após passar pelo leito experimental, ocorreu uma diminuição na concentração de nitrogênio para $0,71 \mathrm{mgL}^{-1}$, o que representa uma eficiência superior a $80,8 \%$ em relação ao efluente bruto e $33,0 \%$ em relação ao leito controle (Figura 6). A provável causa para a redução do nitrogênio nos dois leitos (experimental e controle) é o favorecimento pelos sistemas com fluxo vertical do arraste de oxigênio necessário para que ocorra 0 processo de nitrificação nos leitos (MONTEIRO, 2014). Da mesma forma que o fósforo, o nitrogênio é essencial para as plantas, e a redução de nitrogênio no leito experimental pode ser 0 efeito de absorção desse nutriente pela $E$. acutangula.

A DQO teve média de $479,81 \mathrm{mgL}^{-1}$ no efluente bruto antes da passagem pelos leitos. Os dados deste parâmetro apresentaram maior desvio padrão e uma diferença estatística significativa (Tabela 3) nas amostras do efluente bruto, o que indica uma maior oscilação nas concentrações, acompanhando a variação e quantidades de alimentos processados. A eficiência na remoção de DQO foi superior a $92 \%$ no leito experimental, enquanto que no leito controle foi de apenas $60 \%$ (Figura 6). Os resultados corroboram com os $85 \%$ de remoção de DQO obtidos por Sarnaglia e Gonçalves (2013) em um wetland com fluxo vertical. Esses valores de eficiência para remoção de DQO nos leitos cultivados podem estar relacionados com a maior possibilidade de arraste de oxigênio atmosférico para o interior do substrato que, quando somada com a transferência via macrófitas, atua na intensificação da degradação da matéria orgânica (SEZERINO, 2006).

\section{CONSIDERAÇÕES FINAIS}

Com base na caracterização dos parâmetros do efluente industrial proveniente da central de processamento de alimentos, $80 \%$ dos parâmetros analisados (temperatura, $\mathrm{pH}$, sólidos totais, $\mathrm{DQO}$ e $\left.\mathrm{DBO}_{5,20}\right)$ não estão em conformidade com o estabelecido na Resolução CONAMA № 430 (BRASL, 2011) e na Deliberação Normativa Conjunta № 01 do COPAM-CERH (MINAS GERAIS, 2008), para o lançamento de efluentes. Desse modo, apesar de as baixas concentrações de fósforo e nitrogênio permitirem a infiltração no solo, este efluente necessita de tratamento antes de sua disposição final em cursos d'água. Isso é especialmente importante devido ao fato de o efluente ser gerado continuamente na central de processamento, o que pode ocasionar maiores danos ambientais ao longo do tempo. E, ainda, conforme o baixo valor da relação média da $\mathrm{DQO} / \mathrm{DBO}_{5,20}$, é indicado a inclusão de um tratamento biológico.

Assim, após o tratamento com o leito cultivado com Eleocharis acutangula, houve reduções significativas nos teores de fósforo, nitrogênio e DQO. O leito experimental promoveu a redução de $87,9 \%$ de fósforo, $80,8 \%$ de nitrogênio e $92,69 \%$ de $\mathrm{DQO}$ em relação ao efluente bruto. Em relação ao leito controle sem plantas, o leito com macrófitas reduziu $54,5 \%$ de fósforo, $33,0 \%$ de nitrogênio e $81,4 \%$ de DQO. Além disso, de acordo com as médias desses e dos demais parâmetros analisados, o efluente se tornou apto para a disposição final após o tratamento com macrófitas, conforme os padrões estabelecidos na Resolução do CONAMA № 430/2011 e Deliberação Conjunta do COPAMCERH № 01/2008.

Portanto, este estudo mostra que o leito cultivado com $E$. acutangula tem potencial de uso no tratamento de efluentes gerados em centrais de processamento de alimentos vegetais e de outros tipos de águas residuais com características semelhantes.

\section{AGRADECIMENTOS}

Ao Instituto de Ciências Agrárias (ICIAG) da Universidade Federal de Uberlândia pelo suporte de infraestrutura e materiais. A Nicolas Carvalho 
pelo apoio nas análises laboratoriais e à Dra. Simone Cristina Braga Bertini pelo auxílio nas análises estatísticas.

\section{REFERÊNCIAS}

ABNT. ASSOCIAÇÃO BRASILEIRA DE NORMAS TÉCNICAS. NBR 9897 de 1987: Planejamento de amostragem de efluentes líquidos e corpos receptores. Rio de Janeiro, 22p. 1987a.

NBR 9898 de 1987: Preservação e técnicas de amostragem de efluentes líquidos e corpos receptores. Rio de Janeiro, 22p. 1987b.

APHA, AWWA, WEF. Standard Methods for examination of water and wastewater. Washington, APHA - American Public Health Association, 22nd ed. 1360p. 2012.

AQUINO, S. F. de; CHERNICHARO, C. A. L. Acúmulo de ácidos graxos voláteis (AGVs) em reatores anaeróbios sob estresse: causas e estratégias de controle. Eng. Sanit. Ambient., v. 10, n. 2, p. 152-161, 2005.

BRAILE, P. M.; CAVALCANTI, J. E. W. A. Manual de tratamento de águas residuárias industriais. São Paulo: CETESB, 1993. 764p.

BRASIL. CONSELHO NACIONAL DE MEIO AMBIENTE. Resolução CONAMA № 357, de 17 de março de 2005. Dispõe sobre a classificação dos corpos de água e diretrizes ambientais para o seu enquadramento, bem como estabelece as condições e padrões de lançamento de efluentes, e dá outras providências. Diário Oficial da União, 2005. Brasília. p.58-63.

. Resolução CONAMA № 430 , de 13 de maio de 2011. Dispõe sobre as condições e padrões de lançamento de efluentes, complementa e altera a Resolução no 357, de 17 de março de 2005, do Conselho Nacional do Meio Ambiente-CONAMA. Diário Oficial da União, 2011. Brasília. p.89.

BRITO, J. L. S.; ROSA, R. Elaboração do mapa de solos da Bacia do Rio Araguari na escala de 1:500.000. In: SIMPÓSIO REGIONAL DE GEOGRAFIA, 2, 2003, Uberlândia. Anais... Uberlândia-MG, Universidade Federal de Uberlândia - Instituto de Geografia, 2003.

CALIJURI, M. L.; BASTOS, R. K. X.; MAGALHÃES, T. B.; CAPELETE, B. C.; DIAS, E. H. O. Tratamento de esgotos sanitários em sistemas reatores UASB/wetlands construídas de fluxo horizontal: eficiência e estabilidade de remoção de matéria orgânica, sólidos, nutrientes e coliformes. Revista Engenharia Sanitária e Ambiental, v.14, n.3, p.421430, jul./set. 2009.
COSTA, A. M. G. Desempenho de filtro anaeróbio no tratamento de efluente formulado com diferentes concentrações de soro de queijo. 2008. Dissertação (Mestrado) - Ciência e Tecnologia em Alimentos, Universidade Federal de Viçosa, Minas Gerais, Viçosa, 2008.

DOBLE, M.; KUMAR, A. Biotreatment of industrial effluents. 1. ed. Oxford: Elsevier ButterworthHeinemann, 2005.322p.

EMBRAPA. EMPRESA BRASILEIRA DE PESQUISA AGROPECUÁRIA; EPAMIG. EMPRESA DE PESQUISA AGROPECUÁRIA DE MINAS GERAIS. Levantamento de reconhecimento de média intensidade de solos e avaliação da aptidão agrícola das terras no Triângulo Mineiro. Boletim de Pesquisa № 1. Rio de Janeiro: EMBRAPA/SNLCS, 526p. 1982.

FERREIRA, D. F. Sisvar: a computer statistical analysis system. Ciência e Agrotecnologia, UFLA, v. 35, n. 6, p. 1039-1042, 2011.

GONÇALVES, R. F. (Coord). Uso racional de água e energia: conservação de água e energia em sistemas prediais e públicos de abastecimento de água PROSAB 5. 1. ed. Vitória: ABES, 2009. 352p.

HOFFMANN, H.; PLATZER, C.; WINKER, M.; von MUENCH, E. Technology review of constructed wetlands - Subsurface flow constructed wetlands for greywater and domestic wastewater treatment. Deutsche Gesellschaftfür Internationale Zusammenarbeit (GIZ) GmbH Sustainable Sanitation - Ecosan Program, 2011.

INMET. Instituto Nacional de Meteorologia. Ministério da Agricultura Pecuária e Abastecimento. Gráficos de Normais Climatológicas: $1^{\circ}$ Trimestre do ano (19611990). Disponível em: http://www.inmet.gov.br/portal/index.php?r=clima/norma isClimatologicas. Acesso em: 10 dez. 2016.

MARCELINO, R. B. P.; FRADE, P. R.; AMORIM, C. C.; LEÃO, M. M. D. Tendências e desafios na aplicação de tecnologias avançadas para o tratamento de efluentes industriais não biodegradáveis: atuação do grupo de pesquisas POA Control da UFMG. Revista da Universidade Federal de Minas Gerais, Belo Horizonte, v. 20, n. 2, p. 358-383, jul./dez. 2013.

MARTINS, A. P. L.; REISSMANN, C. B.; FAVARETOO, N.; BOEGER, M. R. T.; OLIVEIRA, E. B. Capacidade da Typhadominguensis na fitorremediação de efluentes de tanques de piscicultura na Bacia do Iraí - Paraná. Revista Brasileira de Engenharia Agrícola e Ambiental, v. 11, n. 3, p. 324-330, 2007.

METCALF, L.; EDDY, H. P. Wastewater engineering treatment and resource recovery. 5. ed. New York: McGraw - Hill Book, 2014. 2018p. 
MINAS GERAIS. CONSELHO ESTADUAL DE POLÍTICA AMBIENTAL. Deliberação Normativa Conjunta COPAM/CERH-MG no 01, de 05 de maio de $2008 . \quad$ Dispõe sobre a classificação dos corpos de água e diretrizes ambientais para o seu enquadramento, bem como estabelece

as condições e padrões de lançamento de efluentes, e dá outras providências. Diário Executivo de Minas Gerais, 2008. Belo Horizonte/MG.

MONTEIRO, V. R. C. Wetlands construídos empregados no tratamento descentralizado de águas cinzas residencial e de escritório. 2014. Dissertação (Mestrado em Engenharia Ambiental) Universidade Federal de Santa Catarina, Florianópolis, 2014.

MOREIRA, S. N.; POTT, A.; POTT, V. J.; DAMASCENO-JUNIOR, G. A. Structure of pond vegetation of a vereda in the Brazilian Cerrado. Rodriguésia - Revista do Jardim Botânico do Rio de Janeiro, v. 62, n. 4, p. 721-729, 2011.

MOREL, A.; DIENER, S. Greywater management in low and middle-income countries. Suíça: Sandec: Department of Water and Sanitation in Developing Countries, 2006.

ORMONDE, V. S. S. Avaliação de 'wetlands' construídos no pós-tratamento de efluente de lagoa de maturação. 2012. Dissertação (Mestrado em Engenharia de Edificações e Ambiental) - Universidade Federal de Mato Grosso, Cuiabá, 2012.

PANSONATO, N. Tratamento e reuso integrado de água cinza utilizando wetlands construídos com plantas ornamentais e um sistema de desinfecção solar. 2010. Dissertação (Mestrado em Tecnologias Ambientais) - Universidade Federal do Mato Grosso do Sul, Campo Grande, 2010.

PHILIPI, L. S.; SEZERINO, P. H. Aplicação de sistemas tipo wetlands no tratamento de águas residuárias: utilização de filtros plantados com macrófitas. 1. ed. Florianópolis: Ed. do Autor, 2004. $144 p$.

POTT, V. J.; POTT, A. Potencial de uso de plantas aquáticas na despoluição da água. Embrapa Documentos 133. Campos Grande, 2002.

RIBEIRO, J. F.; WALTER, B. M. T. As principais fitofisionomias do bioma cerrado. In: SANO, M.S.; ALMEIDA, S.P.; RIBEIRO, J.F. (Ed.). Cerrado: ecologia e flora. Brasília: EMBRAPA-CPAC, p.151-199, 2008.

RUSSELL, D. L. Pratical waster water treatment. 1. ed. Hoboken: John Wiley\& Sons, Inc., 2006. 271 p.

SARNAGLIA, S. A. A.; GONÇALVES, R. F. Uso de "wetland" vertical como pós- tratamento de um filtro anaeróbio a partir de água cinza com vistas ao reuso não potável. In: CONGRESSO BRASILEIRO DE ENGENHARIA SANITÁRIA E AMBIENTAL, 27, 2013, Goiânia. Anais... Goiânia: ABES - Associação Brasileira de Engenharia Sanitária e Ambiental, 2013.

SILVA, J. W.; GUIMARÃES, E. C.; TAVARES, M. Variabilidade temporal da precipitação mensal e anual na estação climatológica de Uberaba, MG. Ciência e Agrotecnologia, v. 27, n. 3, p. 665-674, 2003.

SEZERINO, P. H. Potencialidade dos filtros plantados com macrófitas (constructed wetlands) no pós-tratamento de lagoas de estabilização sob condições de clima subtropical. 171p. 2006. Tese (Doutorado em Engenharia Ambiental) - Programa de Pós-Graduação em Engenharia Ambiental, Universidade Federal de Santa Catarina, Florianópolis, 2006.

SOUSA, J. T.; van HAANDEL, A.; LIMA, E. P. C.; HENRIQUE, I. N. Use of constructed wetland for the post-treatment of domestic sewage anaerobic effluent from UASB reactor. Engenharia Sanitária e Ambiental, v. 9, n. 4, p. 285-290, 2004.

TAVARES, S. R. L.; MAHLER, C. F.; MATTA E ANDRADE, J. C. Fitorremediação: o uso de plantas na melhoria da qualidade ambiental. 1. ed. São Paulo: Oficina de textos, 2013.

UCKER, F. E.; ALMEIDA, R. A.; UCKER, A. P. F. B.G.; KEMERICH, P. D. C. Componentes do sistema de tratamento de esgoto com plantas. Revista do Centro de Ciências Naturais e Exatas, v. 14, p. 2974-2981, 2014.

von SPERLING, M. Introdução à qualidade das águas e ao tratamento de esgotos. 3. ed. Belo Horizonte: Departamento de Engenharia Sanitária e Ambiental, UFMG, 2005.443p. v. 1.

VYMAZAL, J. Horizontal sub-surface flow and hybrid constructed wetlands systems for wastewater treatment. Ecological engineering, v. 25, n. 5, p. 478490, 2005 